\title{
Employees' competitiveness assessment during the skills development to improve the territories sustainability
}

\author{
Inna Kulkova*, and Margarita Litvinenko \\ Ural State University of Economics, 8 Marta Str., 62, 620144 Ekaterinburg, Russia
}

\begin{abstract}
The article proposes a logically linked system of indicators for assessing the employees' competitiveness in the process of qualification upgrading. It was developed by the authors on the basis of a sociological study conducted by using the expert survey method. The survey has confirmed the main study hypothesis that there is the necessity to create tools for a comprehensive employees' competitiveness assessment in order to increase the social and economic sustainability in the territories. Sustainable development can be achieved only by the effective management of the labour force competitiveness growth including in the training process. Criteria that characterize various elements of employee' competitiveness are identified. The indicators' calculating algorithm based on the quantitative and qualitative workers' characteristics is selected among the many methods to assess their competitiveness. The algorithm provides the transformation of employee's qualitative competitiveness characteristics into quantitative ones. The main provisions of employee's competitiveness growth target model in the professional development process are presented in addition.
\end{abstract}

\section{Introduction}

Not only each organization, but also regions' sustainable development depends on the workforce' quality and competence. A number of studies (see the details: [1], [2]) show that even the countries sustainable development is also connected with the employees' competitiveness, and their timely and high-quality training. It is accepted that the countries' economic development is determined not only by researches, innovations, other countries collaboration, but also by the employees' trainings. The workforce quality importance is reinforced at the present stage by such factors as the new equipment and technologies introduction, innovative processes, complicating the labour content and working conditions, the increasing human role in the scientific and technological progress development. In addition, the Covid-19 pandemic, which led to a remote communication format, had an important impact on the revision of approaches to human resources management and the improving their skills process. In particular, the importance of digital competencies is increasing in these conditions [3]. Fundamental transformations are taking place in the

${ }^{*}$ Corresponding author: i.a.koulkova@mail.ru 
advanced training sphere; the revision of the most important aspects concerning the competitiveness assessing foundations in the professional development process, a profound study of its growth prospects and a significant expansion of this area research becomes especially relevant [4]. There is a need to implement new technologies, methods, effective forms of skills development [5] and tools for assessment the employee competitiveness level and the management decisions effectiveness to improve it.

An integral concept for assessing the employee competitiveness has not been created jet, although there are some publications on this problem theoretical understanding. Thus, Ozernikova, Danilenko \& Kravtsevich [6] have defined the employee's competitiveness definition and systematized the variety of its methods. Jurevičiene, D. \& Komarova, A. [7] identified factors for employee's competitiveness assessing, compared different assessment methods, and identified quantitative and qualitative ones. Sotnikova, Maslov \& Glazyrin [8] described the basics of employee competency management. The theoretical basis for assessing the employee's competitiveness can be called the systems theory: a person belongs to a biological (by nature) and natural (way of forming) system [7].

The usage of assessment objects' "competitive advantages" has spread thanks to M. Porter's [9] research, there are enough publications at present devoted to the competitive relations study. Therefore, most often the labour force competitiveness is studied from the labour market point of view [10], [11] or regional differences [12]; the issues of financing the employee competitiveness increase are also studied [13], as well as the competencybased approach usage in companies [14] and the employees competitiveness features in an innovative environment [15]. However, there is a lack of studies about the employees' competitiveness assessment in the skills development process.

Having studied Russian and foreign experience, the authors came to the conclusion that there is no unified, comprehensive methodology currently for assessing the employees' competitiveness in their qualifications improving process. This assessment is of great importance. It takes priority for making specific human resource management decisions and is one of the main points for the employees' competitiveness effective growth. Regular and systematic employees' competitiveness assessment has a positive effect on their motivation, professional development and growth. The lack of fixed criteria and methods of assessment the employees' suitability for work in a specific position ultimately leads to intuitive decisions, non-optimal use of their potential [16].

\section{Methods}

The main hypothesis of the study was that the employees' competitiveness evaluation is possible in the professional development process as well as the effective management of its level. This idea was confirmed in the course of a sociological survey by the expert survey method, conducted by the authors in 2018, 20 respondents were interviewed in total: state authorities' representatives, heads of additional vocational institutions, HR-managers and specialists of personnel services.

The purpose of the study was to obtain information from experts for the tools and guidelines development, which could be used for assessing the level of employees' competitiveness in the advanced training process. The study made it possible to identify some significant trends in the employees' competitiveness assessing in the training process.

The preliminary analysis of the existing employees' competitiveness assessing system allows to conclude that the competitiveness assessing process is carried out currently only according to those indicators that characterize the employees' competitiveness within the company, and is generally systemic, but formal by nature. Insufficiently high employees' competitiveness level and untimely managerial decisions adoption to improve it are a consequence in Russia. The alleged reason for this is the lack of an independent, 
comprehensive competitiveness assessment and its ineffective growth level management, although it is possible in the professional development process.

In accordance with the main hypothesis, the questionnaire contained blocks of questions: about indicators characterizing the employees' competitiveness, its assessment methods, their effectiveness and efficiency, the advanced training role in the employees' competitiveness growth.

Additional hypotheses were:

1. The professional development process is aimed at regular improvement of employees' professional abilities, business qualities and personal characteristics in the constantly changing conditions of professional activity and social environment. It can be more effective when it takes into account the results of workers' competitiveness assessing, which, in turn, are necessary for the effective employees' competitiveness management.

2. Employees' competitiveness study, limited to assessment at the organization level, may be due to the lack of: a) a clear mechanism for interaction between companies, state and municipal authorities and educational institutions while employees' competitiveness assessing process; b) methods for employees' competitiveness assessing and the effectiveness of its level growth managing in the professional development process.

3. When choosing an educational institution for vocational training, educational services consumers face uncertainties due to: a) the lack of an advertising campaign conducted by educational services providers about the vocational training quality and potential development level changes (shifts); b) weak awareness of the companies' personnel services in all industries about the determined priorities of effective HR-management and ensuring the constant their competitiveness growth in the professional development process.

To test the main hypothesis, the authors identified the structure of indicators that characterize most fully the labour force competitiveness in the advanced training process.

To test additional hypotheses, it was proposed to solve the following problems:

- to determine the respondents' attitude towards the professional development process and the role of the employees' competitiveness assessment results in the effective management decisions development to improve it;

- to explore the respondents' opinion about the social partnership importance in the employees' competitiveness assessment in the professional development process;

- to study the existing systems for the employees' competitiveness assessment and to determine the most effective and efficient assessment methods;

- to reveal the respondents' attitude towards the need to inform educational services consumers about the training quality and on improving the employees' competitiveness;

- to find out the respondents' opinion about the management decisions objectivity based on the employees' competitiveness assessment during the professional development.

The questionnaire included 23 questions, which can be divided into three main groups:

1. The need to assess the employees' competitiveness;

2. The universal tools' creation for employees' competitiveness assessment;

3. The employees' competitiveness assessment possibility in the professional development process.

Some general questions were too included in the questionnaire such as:

- What does the Professional Development Process involve?

- What is employee's competitiveness?

The questionnaire included also problematic issues, which presentable solution is possible at the regional level: about the social partnership forms in the improving the employees' qualifications process; on cooperation between authorities, producers and 
consumers of educational services; on the management decisions development to improve the employees' competitiveness in the further training process.

\section{Results}

Summarizing the interpretations of the employees' competitiveness concept given by experts, it can be concluded that it is considered as a set of workers' professional and personal qualities, characterizing the ability to carry out labour activities during being employed, as well as looking for a work on the labour market.

The results of the study indicate that the advanced training process is presented as a continuous education process for most experts, which implies continuous improvement of professional knowledge, skills and abilities, the formation and development of competencies necessary in professional activity. Some consider the professional development as a system that allows to benefit not only the educational services consumer, but the state and society as a whole.

Three quarters of the respondents answered that success in professional activity had been achieved as a result of together taken professional retraining, advanced training, selfeducation and internships, $15 \%$ - as a result of professional retraining, and $5 \%$ each advanced training and retraining.

According to the respondents, the professional development process is aimed towards the constant improvement of the person's knowledge, skills and abilities, caused by the need to "keep up with the times", the desire to be in demand in the existing professional and social environment. Furthermore, it also aims to meet the regional needs in providing qualified personnel adapted to the constantly changing conditions of professional activity and social environment. The smallest number of answers were received by such questions as - strengthening, combining the regional educational resources, ensuring the training individualization using new technologies, the most promising technical means.

$35 \%$ of the respondents believe that the main training goal is to educate the "new formation" employees that meets the constantly changing requirements of the professional and social environment; $20 \%$ - obtaining the competence necessary to perform a new type of professional activity; $15 \%$ - obtaining and updating knowledge on the current activity sphere; $10 \%$ each, respectively - the employees' professional, business, personal and other qualities development, their competitiveness formation and increase.

The majority of experts $(60 \%)$ came to mind that the assessment by independent organizations makes it possible to determine the employees' competitiveness state objectively and to facilitate management decisions timely to improve it (85\%). More than two-thirds of the respondents answered this way. $90 \%$ of the experts confirmed that the interaction between companies, state and municipal authorities and additional training institutions contributes to the most effective and comprehensive employees' competitiveness assessment.

The main forms of social partnership, according to the respondents, are:

- united program implementation of improving the employees' competitiveness;

- joint development and implementation of human resources policy by partner representatives based on a balance of state, employers and employees' interests;

- information exchange.

When being asked about the importance of cooperation between government and management authorities, educational services producers and consumers in employees' competitiveness assessing in the advanced training process and the managerial decisions development to improve it, $75 \%$ of experts conformed the importance of determining the priorities, first of all, for effective employees' competitiveness management and the ensuring a constant competitiveness growth in the companies' staffing. $15 \%$ believe that 
such cooperation is assumed by the principles of the state human resources policy of the Russian Federation; $10 \%$ - that it is necessary to strengthen social partnership in the improving the qualifications process.

$60 \%$ of respondents suppose that it is possible to determine the priorities of effective HR-management based on the independent employees' competitiveness assessment in the professional development process. In addition, $55 \%$ of the interviewed experts agreed that the internal employees' competitiveness assessment and the management decisions development to improve it at the company level is not effective enough; this problem can be solved by specialists' involvement.

According to the research results, the most effective methods for the labour force competitiveness assessment are complex ones, that are used for studying quantitative labour results indicators and for assessing qualitative indicators. $90 \%$ of respondents noted that employees' competitiveness assessing requires the usage of a whole range of different methods aimed to assess compliance with a variety of indicators and criteria. In addition, $90 \%$ of the respondents believe that it is possible to assess the employees' competitiveness and to determine its improvement concept using a single comprehensive methodology for calculating indicators characterizing the employees' competitiveness.

It can be concluded that it is necessary to use a single comprehensive methodology for employees' competitiveness assessment, which allows to study quantitative and qualitative indicators characterizing the competitiveness (if necessary, quantitative indicators can be converted into qualitative ones, and vice versa).

According to the expert survey results, personal and qualification potentials affect the employees' competitiveness growth level to a greater extent in the advanced training process, and the training effectiveness - to the least extent.

The qualification potential, as one of the elements of the employees' competitiveness, is understood as the totality of employee's characteristics and abilities (professional, intellectual, psychophysiological, etc.), such as: the educational level, the discipline, the academic performance (during employee's advanced training).

Personal potential refers to the totality of an employee's business and professional qualities [17]. Personal potential "includes not only the potential content of the personality (abilities, naturally determined professionally important qualities, positive hereditary factors), but also a system of constantly renewed and multiplied resources - intellectual, psychological, volitional, which contributes to progressive personal and professional development" [18].

The training effectiveness (educational progress) acts as a generalizing indicator in employees' competitiveness assessment in the skills development process, which characterizes not only the training effectiveness, but also the effectiveness of the employees' competitiveness growth level.

As a result of the study, the authors also revealed the importance of indicators characterizing the qualification potential, determining the workers' professional qualities development level and those that allow to assess their business qualities in the improving qualifications process.

Among the criteria characterizing the employees' qualification potential in the advanced training process, experts identified four of them. They consider the employees' educational level to be the most important criterion; this criterion scored 3.4 out of 5 points. Next by its importance is the quality of training, which is defined as the ratio of the number of trained workers who received the highest marks to the total number of workers admitted to the exam; the criterion scored 2.7 points. The interviewed experts consider the discipline criterion is also important, which means the presence or absence of labour discipline violation cases (for example, absenteeism) (2.1 points), and stability, which is defined as 
the ratio of those who were expelled from advanced training courses to the average number of trainees (1.9 points).

To assess the employees' business qualities in the improving qualifications process, the experts named the following most important criteria: professionalism as highly developed professional competence (this criterion significance was 4.0 points out of 5 according to the survey results); educational level (3.8 points); quality of training (2.6 points); training level, which is calculated as the ratio of the number of trainees who received a positive assessment to the total number of people who passed the exam (2.5 points) and discipline (2.3 points).

According to the interviewed experts, the employees' professional qualities assessment in the professional development process, can be carried out using the following criteria: qualifications (this criterion received 2.6 points out of 5); work experience (2.3 points) and the frequency of professional development (1.2 points).

The importance of the employees' business and professional qualities on the training effectiveness has been determined. $70 \%$ of the surveyed experts believe that professional qualities are more important, and 30\% - that business qualities are more important.

The employees' competitiveness is not a constant value, it changes over time (increases or decreases), and, therefore, it can be controlled by influencing the relevant qualification and personal components, the assessment of which can be determined in quantitative and qualitative indexes using the methodology for determining indicators, characterizing the employees' competitiveness.

Since the employees' competitiveness is a combination of their quantitative and qualitative characteristics, through which the ability to work is realized, it should be considered from its structured point of view, i.e. constituent elements (characteristics) possessed by a person, organization, society, and which can be changed, evaluated, analysed to establish trends in the employees' competitiveness, respectively, the impact on the competitiveness of both the employee and the team or a separate industry as a whole. Component indicators characterizing the employees' competitiveness level are presented in Fig. 1 . 


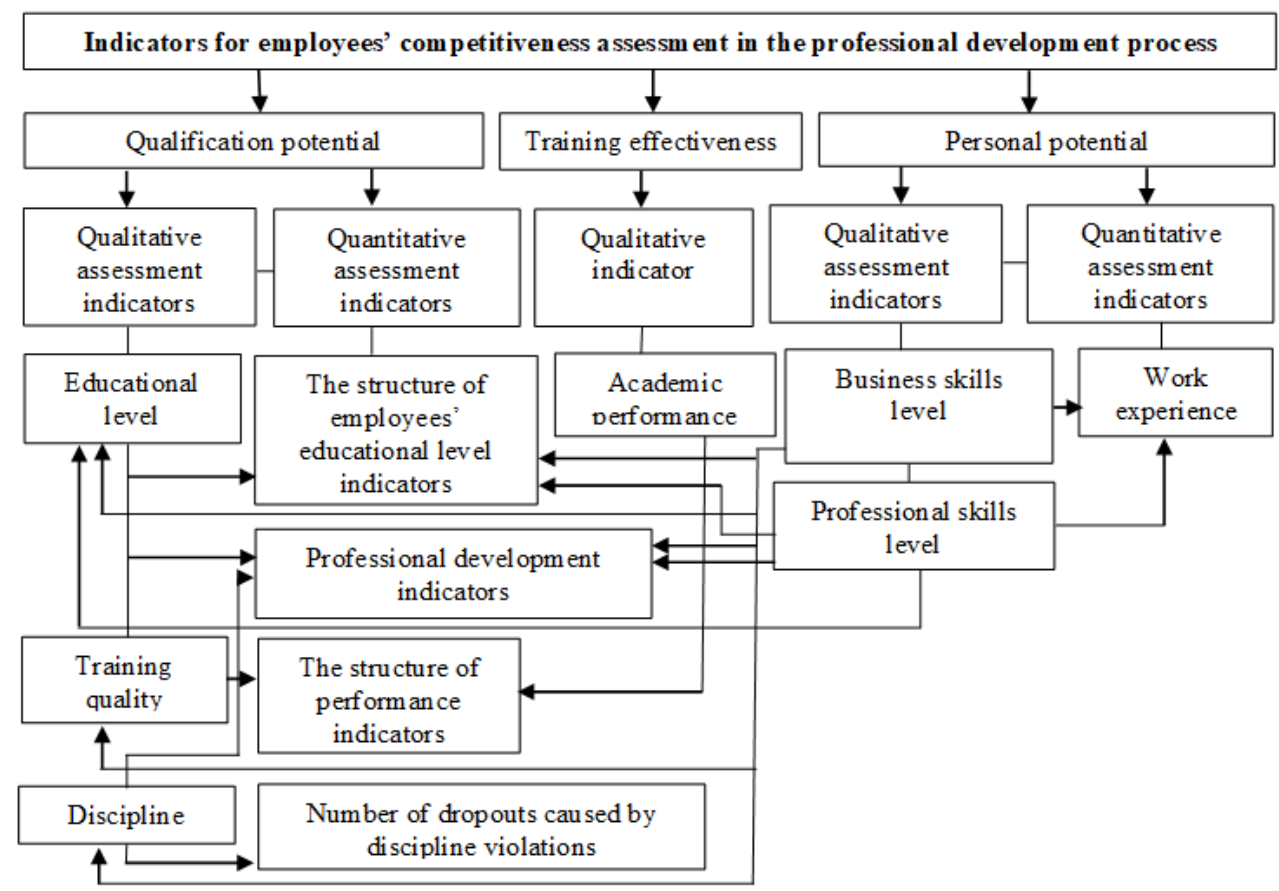

Fig. 1. Indicators for employees' competitiveness assessment in the professional development process

\section{Conclusion}

Having conducted a study of indicators characterizing the employees' competitiveness, the authors have created a basis for the methodology development that allows to make an its objective assessment in the professional development process and to model the process of managing the employees' competitiveness level.

Thus, the results of the conducted expert survey made it possible to reveal the possibilities of a comprehensive employees' competitiveness assessment and its level managing effectiveness in the advanced training process and to confirm the main and additional hypotheses of the study that the employees' competitiveness assessment in the advanced training process has been systemic, but formal recently. Consequently, there are no a sufficiently high employees' competitiveness level and not timely its growth managerial decisions development. The reason for this is the lack of its growth, which implementation can be carried out in the professional development process, has also been confirmed.

To increase the employees' competitiveness level in the skills development process, the authors propose the following basic provisions of the target model:

- Implementation of strategic and regulatory documents of human resource policy.

- Further employee training efficiency and quality improvement in the professional development process.

- Continuous improvement of management moderation, methodological, material and educational support and software.

- Professional development process modernization.

The monitoring of the employees' competitiveness level in the professional development will allow to assess the compliance the competitiveness level with the company's goals, and to plan measures aimed at it increasing. The employees' 
competitiveness assessing methodology in the professional development process should be transparent, operative, accessible to all assessment objects. It should be based on the private indicators combined into an interconnected system. It is advisable to assess the employees' competitiveness in the qualifications improving process through an objective, comprehensive and relevant analysis of information characterizing the employees' competitiveness level, identifying problem areas and opportunities to improve and predict the employees' competitiveness level.

\section{References}

1. H. Yan Cheung, A.W.H. Chan, Int. J. of Manpower, 33(2) (2012)

2. H. Yan Cheung, A.W.H. Chan, L. Benton, T.R. Bailey, T. Noyelle, T.M. Stanback, Employee Training and U.S. Competitiveness: Lessons for the 1990s (2019)

3. P.Y. Grosheva, N.V. Bondarchuk, Contributions to Economics, F2 (2019)

4. M.S. Litvinenko, Materials of the regional competition for the best scientific work among students and graduate students (young scientists) of educational institutions of higher school and scientific institutions of the Kurgan region (2017)

5. I.A. Kulkova, M.I. Plutova, E.A. Kuryachaya, IOP Conference Series: Earth and Environmental Science 272 (3) (2019)

6. T.G. Ozernikova, N.N. Danilenko, S.V. Kravtsevich, Employee competitiveness: concept, research, management (2007)

7. D. Jurevičiene, A. Komarova, Business: Theory and Practice, 11(2) (2010)

8. S.I. Sotnikova, E.V. Maslov, S.Yu. Glazyrin, Personnel competitiveness management (2006)

9. M.E. Porter, Competitive Advantage (1985)

10. Z.T. Golenkova, G.B. Kosharnaya, V.P. Kosharnyy, Integration of Educ., 22(2) (2018)

11. A.M. Balkhanov, VEO of Russia Today, 2 (2015)

12. A.M. Balkhanov, Zh.T. Chagdurov, Human Progress, 2(5) (2016)

I. Perevozova, N. Daliak, V. Babenko, CEUR Workshop Proceedings, 2422 (2019)

13. A.A. Bey, E.N. Bavykina, Human Progress, 4(2) (2018)

14. S.G. Zemlyanukhina, E.V. Yanchenko, L.V. Sankova et al., Competitiveness of labor resources in the conditions of innovativeness of the Russian economy (2010)

15. O.V. Bespalova, Innovative Economy: Prospects for Development and Improvement, 1 (2014)

16. S.G. Radko, ISJ Theoretical \& Applied, 75 (2019)

17. A.A. Derkach, V.G. Zazykin, Acmeology (2003) 